\title{
Predatory Capacity of Anabantoids Indigenous Fishes (Beta Pugnax and Beta Anabatoides) on the Mosquito's Larvae
}

\author{
Faez Firdaus Jesse Abdullah ${ }^{* 1}$, Eric Lim Teik Chung ${ }^{1}$, Yusuf Abba ${ }^{2}$, \\ Konto Mohammed ${ }^{1}$, Abdulnasir Tijjani ${ }^{1}$, Muhammad Abubakar Sadiq ${ }^{1}$, \\ Lawan Adamu ${ }^{3}$, Idris Umar Hambali ${ }^{1}$, Asinamai Athliamai Bitrus ${ }^{2}$, \\ Mohd Azmi Mohd Lila², Shaikh Mohd Amin Babjee ${ }^{2}$, Hassan Hj.Mohd. Daud ${ }^{2}$ \\ ${ }^{I}$ Department of Veterinary Clinical Studies, Faculty of Veterinary Medicine, Universiti Putra Malaysia, 43400 \\ Serdang, Selangor, Malaysia, \\ ${ }^{2}$ Department of Veterinary Pathology and Microbiology, Faculty of Veterinary Medicine, Universiti Putra \\ Malaysia, 43400 Serdang, Selangor, Malaysia, \\ ${ }^{3}$ Department of Veterinary Medicine, Faculty of Veterinary Medicine, University of Maiduguri, PMB1069, \\ Borno State, Nigeria.
}

\begin{abstract}
A study was carried out to determine the maximum intake of mosquitoes' larvae within a twenty four hours period by two species of indigenous Anabantoids. The species used were Betta pugnax and Betta anabantoides and for each species five adult male fish were used. The feeding of the mosquito larvae every twenty four hours period was observed continuously for three days for each species. The mean standard length of the Betta pugnax and Betta anabantoides were $3.8 \mathrm{~cm}$ and $3.7 \mathrm{~cm}$ respectively and for the mosquitos' larvae, the length varies from $5-6 \mathrm{~mm}$. The mean intake of mosquitoes larvae counted for every twenty four hours for 3 days was 24.5 larvae for Betta pugnax and 16.7 larvae for Betta anabantoides. From this study it was concluded that Betta pugnax has a significantly $(P<0.05)$ higher predatory capacity as compared to Betta anabatoides.

Keywords: Predatory capacity, Anabantoids, indigenous fishes, mosquitoes' larvae
\end{abstract}

\section{Introduction}

The mosquito of the family Culicidae is described as small slender flies with humped thorax and long legs. This family contains over 3000 species belonging to 34 genera. The most important genera include Aedes, Anopheles, Culex, and Psorophora. All mosquitoes need water body to complete their life cycle [1]. These water bodies can range in quality from melted snow to sewage effluent and can be in any container imaginable [2]. The type of water in which the mosquito larvae is found can be an aid to the identification of which species it may be [3]. Adult mosquitoes show a very distinct preference for the types of sources in which to lay their eggs. They lay their eggs in such places such as tree holes that periodically hold water, tide water pools in salt marshes, sewage effluent ponds, irrigated pastures and rain water ponds. Each species therefore has unique environmental requirements for the maintenance of its life cycle. Eggs are laid one at a time and they float on the surface of the water. In Culex and Culiseta species, the eggs are stuck together in rafts of a hundred or more eggs; while Anopheles and Ochlerotatus species do not make egg rafts but lay their eggs separately. Most eggs hatch into larvae within 48 hours [1].

The pathogenic significance of mosquitoes consists mainly of severe annoyance, blood loss, and transmission of several fatal diseases. The toxins that are injected at the time of biting may cause systemic effects. Mosquitoes are known for spreading malaria, yellow fever, dengue, and encephalitis in man and other primates [4]. The mosquito act as intermediate host in transmitting diseases for example Anopheles quadrimaculatus is the intermediate host for malaria (Plasmodium spp) whereas Aedes albopictus is important in spreading dengue fever which becoming a threat to many tropical countries of the world.

There are over one hundred species of Anabantoids that are currently traded in the tropical fish industry of which about thirty species are in the genus Betta. All the Anabantoids are commonly known as the labyrinth fishes. These fishes are characterized primarily by an accessory organ called the labyrinth organ. The labyrinth organ is located next to the gill cavities and is made up of folded membranes mounted on a bony frame. The delicate tissue has a higher concentration of blood vessels and functions much like the terrestrial lung [5-7].

Betta pugnax (ikan Karin) and Betta anabatoides (ikan Sepilai) are native to Peninsular Malaysia [8]. Betta pugnax are normally found in the northern region of Peninsular, mainly Penang [9]. Betta anabatoides are normally found in Asia and Island of Borneo [10]. This Anabantoids fishes are considered carnivorous, their natural diet being different species of invertebrates [11]. These fishes are normally found in clear stagnant acidic water especially in paddy fields and associated shallow waterways, rubber estates, coconut plantations or in slow moving small streams. These fishes also naturally inhabits in the shallow thickly vegetated areas of rivers, 
canals, ditches, lakes and swamps and such habitats protects them from predators such as birds or other fish species [12].

Based on the report by Riehl, et al. (1991), the Betta spp. feeds on mosquitoes' larvae, insects, and some species of invertebrates [13]. In nature Bettas subsist almost exclusively on insects and insect larvae. They are adapted with an upturned mouth that is well suited to snatching any helpless insect that might fall into the water. Internally, their digestive system is geared for meat. Animals are an important immunobiologics for potential human application [14,15]. Thus, this study was conducted to determine the maximum intake of mosquitoes' larvae within a twenty four hours period by two species of indigenous Anabantoids.

\section{Fish Source and Stabilization Process}

\section{Materials and Methods}

A total of ten Anabantoid fishes were used in this experiment. The Betta pugnax (Figure 1) and the Betta anabatoides (Figure 2) were obtained from Penang and Selangor States of Peninsular Malaysia respectively. For acclimatization to the experimental environment, all the fishes were kept individually in separate containers containing some aquatic plants (Figure 3). The containers used to keep this fishes were clear round plastic having a diameter of $11 \mathrm{~cm}$ and height $15 \mathrm{~cm}$. After stabilization for a month the fishes were trained to feed on mosquitoes larvae from pipette. Fish sexing was done by looking at the morphology of the dorsal fins, stomach region and the color of the fish. Only male fishes were used for this experiment. The size of the fish that were selected for this experiment is based on the standard body length of the fish and it varied from 3.5 to $3.9 \mathrm{~cm}$.

\section{Collection of Mosquitoes' Larvae}

Fifteen aquaria and ten plastic buckets were used and water used for the breeding of mosquitoes was $50 \%$ tap water and $50 \%$ pond water. The tanks were observed for the presence mosquitoes larvae every day. If the larvae were observed, the containers will be closed with wire nets and kept until the larvae reach the length that was needed which varies from $5 \mathrm{~mm}$ to $6 \mathrm{~mm}$.

\section{Collection of Larvae and Feeding of the Fish}

Pipette was used to suck the mosquito larvae from the breeding tanks. They were collected when they were about 5-6 $\mathrm{mm}$ in length. The collected larvae were immediately used to feed the fishes using plastic pipette and at the same time the number of larvae were counted. The fishes were fed continuously for three days with mosquito larvae and the maximum intake was recorded. The maximum number of larvae consumed by the fish was then recorded after the fish refused to feed anymore and showed no interest towards the larvae.

\section{Setting up aquarium tank with fish and without fish}

An aquarium was set with a pair of Betta pugnax and the aquarium without any fish was placed in between the mosquitoes breeding aquarium tanks. The aquarium with the fish were observed daily for two weeks continuously to see whether there are any mosquito larvae developed in the tank.

\section{Results}

The results showed that both Betta pugnax and Betta anabantoides are voracious feeder of mosquitoes' larvae. The maximum mean intake of mosquitoes' larvae for every 24 hours period was higher in Betta pungnax as compared to Betta anabatoides. The maximum mean intake during the three day period for Betta pugnax was 26 larvae whereas for Betta anabatoides was 17 larvae (Figure 4). Statistically, there was significantly difference in the maximum mean intake of mosquitoes' larvae for every 24 hours period between Betta pugnax and Betta anabatoides $(\mathrm{P}<0.05)$. From the results of the daily intake the Betta pugnax has a higher predatory capacity than Betta anabatoides.

From a two-week observation, no mosquito larvae were found in the tank with Betta pugnax. For the control tanks without the fish, numerous mosquitoes' larvae can be observed within three to five days after the tank was placed.

\section{Discussion}

In nature Bettas subsist almost exclusively on insects and insect larvae [11]. This anabantoids fish is considered carnivorous, where the natural diet being different species of invertebrates [11]. The results of this study show that Betta pugnax and Beta anabatoides were voracious feeder of mosquitoes' larvae. Similar findings were reported for Betta splendens [16].

The maximum mean intake of mosquitoes' larvae for every 24 hours for a 3-day period was higher in Betta pugnax as compared to Betta anabatoides. From the current study, Betta pugnax was observed to be more active and move at a faster rate towards to the prey as compared as to the Betta anabatoides and this can be 
possibly the reason why Betta pugnax has higher intake of larvae compared to the Betta anabatoides. Another possible reason is due to the morphology of the fish where the Betta pugnax has a more rounded abdomen compared to the Betta anabatoides where the abdomen is more laterally compressed.

From observation, this Betta species response to their prey that is actively moving in the water as compared to the prey that is inactive or prey that is not alive. Degani, (1990) reported that Betta's ideal food will be the live food [11]. The reason why these Betta's move more towards the moving objects or prey in the water is that the species has an excellent acousticolateralis system. This acousticlateralis system of fish senses sounds, vibrations and other displacements of water in the environment. The lateral line of fish provides a fern tastsinn or 'distant touch' sense [17]. This lateral line in the fish will allow it to detect water movements around the fish.

Neng, (1987) reported that the use of predatory fish such as catfish (Clarias sp) in water tanks will help reduce the number of mosquitoes' larvae [18-21]. From the two weeks observation no mosquitoes' larvae were found in the tank with Betta pugnax. From this study we can conclude that Betta spp. can be used as one of biological control agents in reducing the population of mosquitoes' larvae. The predatory behavior of this Betta's can be used as control of mosquitoes in water containers within a house and this may help to reduce the incidence of mosquito borne disease. Gubler, (1989) reported that household storage of water in open containers has frequently been the cause for outbreaks of human disease transmitted by Aedes aegypti [22].
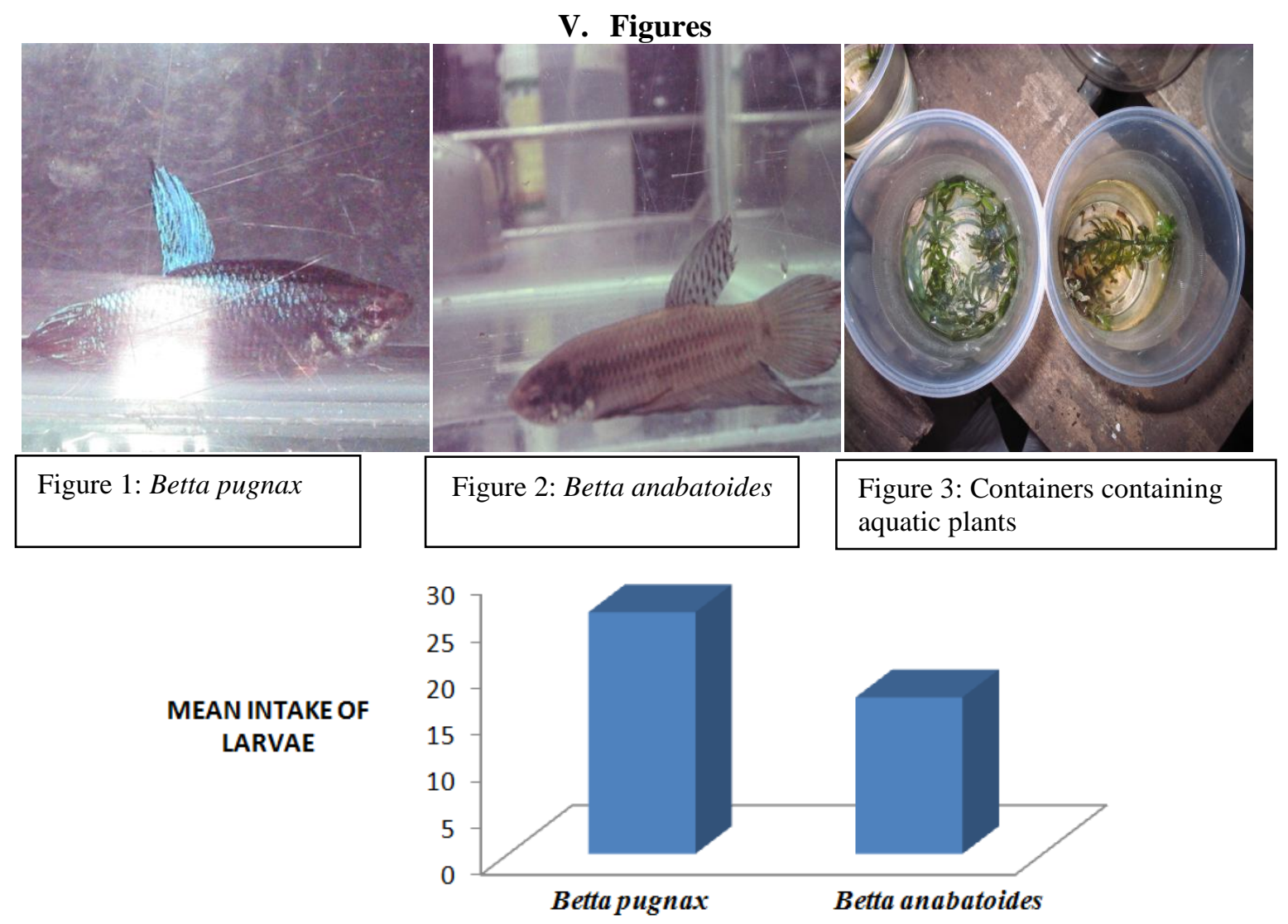

FISH SPECIES

Figure 4: Mean intake of mosquitoes' larvae during the three day period for Betta pugnax and Betta anabatoides.

\section{Conclusion}

Generally from this experiment, it can be concluded that indigenous Bettas can be used as biological control agent to reduce the population of the mosquitoes of which Beta pugnax found to have higher mosquito larva intake/feeding capacity.

\section{Acknowledgement}

The authors wish to acknowledge University Veterinary hospital (UVH), and Faculty of Veterinary Medicine Universiti Putra Malaysia for their technical assistance. 


\section{References}

[1] G.M. Urquhart, J. Armour, J.L. Duncan, and F.W. Jennings, Veterinary Parasitology $2^{\text {nd }}$ Edition. (Oxford, Blackwell science, 1996).

[2] M.M. Khaleel, F.F.A. Jesse, A.Y. Osman, A. Wahid, M. Zamri-saad, and A. Rahman, Acute phase protein responses in mice affected with river water contaminated by Pasteurella multocida type B2. American Journal of Animal and Veterinary Sciences, 8 , 2013, 159-164.

[3] P.J. Lester, and A.J. Pike, Container surface area and water depth influence the population dynamics of the mosquito Culex pervigilans (Diptera: Culicidae) and its associated predators in New Zealand. Journal of Vectoe Ecology, 28, 2003, $267-274$.

[4] C.M. Kahn, and S. Line, The Merck Veterinary Manual $9^{\text {th }}$ Edition. (USA, Merial, 2005).

[5] V.C. Chong, P.K.Y. Lee, and C.M. Lau, Diversity, extinction risk and conservation of Malaysian fishes. Journal of Fish Biology, 76, 2010, 2009-2066.

[6] A.R. Zulkafli, M. Asmuni, A.G. Hassan, B. and Haslawati, Ikan-ikan air tawar Sungai Pahang (Freshwater fishes of Pahang River). (Department of Fisheries, Malaysia, 2014).

[7] Z.A. Rashid, M. Asmui, and M.N.A. Amal, Fish diversity of Tembeling and Pahang rivers, Pahang, Malaysia. Biodiversity Data Journal, 11, 2015.

[8] Donoso-Buchner, and Schmidt. (1997). http://fishbase.org.

[9] H.H. Tan, and S.H. Tan, Redescription of the Malayan fighting fish Betta pugnax (Teleostei: Belontiidae), and description of Betta pulchra, new species from Peninsular Malaysia. Raffles Bulletin of Zoology, 44, 1996, 419-434.

[10] M. Kottelat, A. J. Whitten, S.N. Kartikasari, and S. Wirjoatmodjo, Freshwater Fishes of Western Indonesia and Sulawesi. (Hong Kong, Periplus Editions (HK) Ltd, 1993)

[11] G. Degani, Effect of Different Diets and Water Quality on the Growth of the Larvae of Trichogaster trichopterus (B\&S 1801). Aguaculture Engineering, 9, 1990, 367-375.

[12] E.L.T. Chung, F.F.J. Abdullah, L. Adamu, A.D. Marza, H.H. Ibrahim, M. Zamri-Saad, A.W.Haron, A.A. Saharee, M.A.M. Lila, A.R. Omar, M.Z.A. Bakar, and M.J. Norsidin, Clinico-pathology, hematology and biochemistry responses towards Pasteurella multocida type B: 2 via oral and subcutaneous route of infections. Veterinary World, 8, 2015, 783-792.

[13] R. Riehl, and H.A. Baensch, Aquarium Atlas. (Germany, Mergus, Melle, 1991).

[14] H. Hani, T.A. Ibrahim, A.M. Othman, M.A. Mohd-Lila, and Z.N. Allaudin, Isolation, density purification, and in vitro culture maintenance of functional caprine islets of Langerhans as an alternative islet source for diabetes study. Xenotransplantation, 17, 2010, 469-480.

[15] H. Hani, Z.N.Allaudin, M.A. Mohd-Lila, T.A. Ibrahim, and A.M. Othman, Caprine pancreatic islet xenotransplantation into diabetic immunosuppressed BALB/c mice. Xenotransplantation, 21, 2014, 174-182.

[16] W.J. Rainboth, Fishes of the Cambodian Mekong. FAO Species Identification Field Guide for Fishery Purposes. (Rome, FAO, 1996).

[17] S. Dijkgraaf, The functioning and significance of the lateral-line organs. Biological Reviews, 38, 1962, 51-105.

[18] W. Neng, H. Shusen, X. Guangxin, T. Rongman, Q. Guangkun, and Chen, Control of Aedes aegypti larvae in household water containers by Chinese cat fish. Bulletin of the World Health Organization, 65, 1987, 503-506.

[19] A.S.R.M. Shah, B.S. Ismail, M. Mansor, and R. Othman, Diversity and distribution of fish in irrigation water derived from recycled and uncontrolled flow water sources in the Muda ricefields. Pertanika Journal of Tropical Agriculture Science, 33, $2010,213-222$.

[20] A.R. Khairul-Adha, Y. Esa, and A. Arshad, The influence of alien fish species on native fish community structure in Malaysian waters. Kuroshio Science, 7, 2013, 81-93.

[21] A. Siti-Zahrah, M. Zamri-Saad, M.Firdaus-Nawi, M.K.Hazreen-Nita, and M. Nur-Nazifah, Detection of channel catfish virus in cage-cultured Pangasius hypophthalmus (Sauvage, 1878) in Malaysia. Journal of Fish Diseases, 37, $2014,981-983$.

[22] D.J. Gubler, Aedes aegypti and Aedes aegypti-borne disease control in the 1990's (Centers for Disease Control, 1989). 